\title{
Influence on Cheddar cheese proteolysis and sensory characteristics of non-starter strain Lactobacillus plantarum
}

\author{
Weiwei $\mathrm{Bi}^{1,2,4, a}$, Guixing Zhao 2, 3, 4, b, *, Guangjin Wang ${ }^{2, c}$, \\ Bixian Zhang 1, 2, d, Shuwen Lu 5,e, Haofei Liü, f, Jinrong Li², g, Lei Chen², h \\ 1 Heilongjiang Academy of Agricultural Sciences Post-Doctoral Station, Harbin150086, China \\ ${ }^{2}$ Soybean Research Institute, Heilongjiang Academy of Agricultural Sciences, Harbin150086, \\ China \\ ${ }^{3}$ College of Food Science and Engineering, Harbin University of Commerce, Harbin 150076, China \\ ${ }^{4}$ Grain \& Corn Engineering Technology Research Center, China State Administration of Grain \\ ${ }^{5}$ Institute of Food Research, Heilongjiang Academy of Agricultural Sciences, Harbin150086, China \\ aCCorresponding Author: weiwebi5321; bzhaoguixing@163.com; 'gjw1962@126.com; \\ dhljsnkyzbx@163.com; eshuwenl@sina.com, fliuhaofei1983@163.com; '9sylijr@126.com; \\ h1540182002@qq.com
}

Keywords: Lactobacillus plant arum, proteolysis, adjunct cultures, Cheddar cheese ripening, Cheese sensory.

\begin{abstract}
The contribution to Cheddar cheese proteolysis and sensory profile of one potentially nonstarter strain Lactobacillus plantarum was assessed. Lactobacillus plantarum was able to grow in Cheddar cheese, where it maintained high levels during ripening. Overall, adjunct culture of Lactobacillus plantarum significantly influenced secondary proteolysis from the beginning of ripening. The changes observed were consistent with the acceleration of proteolysis in the Cheddar cheese models assayed. Moreover, Cheddar cheese added with Lactobacillus plantarum had good flavour characteristics compared to controls, their other sensory characteristics were improved, and they did not show any defects. Lactobacillus plantarum had desirable and robust technological properties, which made it a suitable adjunct culture for cheese making.
\end{abstract}

\section{Introduction}

Cheese contains a complex combination of microorganisms that changes with time, initially containing large numbers of starter lactic acid bacteria (SLAB) and then with maturation, an increasing number of NSLAB $[1,2]$. At present, some studies found that some NSLAB have been shown to contribute to an increase in free amino acid development and influence flavor development. To the best of our knowledge, no studies have been conducted on the contribution of Lactobacillus plantarum isolated from traditional Chinese northeast fermentation food to proteolysis and sensory in Cheddar cheese.Fresh Cheddar curds were made under controlled conditions to minimize the influence of wild nonstarter microflora in the slurries to which nonstarter lactobacilli were added. The greatest contributing factor to Cheddar cheese quality during ripening is proteolysis. The nonstarter organisms contribute to an increase in peptidase activity in cheese and enhance the production of peptides and amino acids [3].

This study was aimed at using Cheddar cheese to evaluate the selection of nonstarter Lactobacillus plantarum. The isolated strain Lactobacillus plantarum was used individually as nonstarter to assess the proteolytic activities and sensory during ripening of Cheddar cheese. In this research Cheddar cheeses made with Lactobacillus casei and no strain as adjuncts separately were control ones. All cheeses were ripened for 60 days and assessed for composition, texture, microbiology, proteolysis and sensory property. 


\section{Materials and Methods}

\subsection{Cultures}

Commercial Cheddar culture was obtained from Chr. Hansen. Lactobacillus casei 1.0319 belonging to the Culture Collection of the Key Laboratory of Dairy Science of Ministry of Education, Northeast Agricultural University, China and Lactobacillus plantarum 23058 used in this study, had been isolated previously from"suan cai" and identified as Lactobacillus plantarum by $16 \mathrm{srDNA}$. All strains were routinely cultured in MRS broth (Difo) at $37^{\circ} \mathrm{C}$, and maintained in MRS broth supplemented 25\% (v/v) with glycerol and stored at $-80{ }^{\circ} \mathrm{C}$.

\subsection{Compositional analysis}

Cheddar cheeses were manufactured from standardized pasteurized milk $\left(63{ }^{\circ} \mathrm{C}, 30 \mathrm{~min}\right)$ by the method[4]. Cheddar cheese was added with Lactobacillus casei as control 1, no adjuncts starters as control, Lactobacillus plantarum as test group. Cheese composition was analyzed on the day of manufacture. Moisture content of the cheeses was determined by the method of an oven drying [4], fat by the Gerber method[5], total protein by the macro-Kjeldahl procedure[6] and salt content[7]. All determinations were carried out on three different sections of each cheese and values were averaged.

\subsection{Microbiological analysis}

Bagged cheese were placed into sanitized anaerobic chambers and incubated at $30^{\circ} \mathrm{C}$. Each bag was removed from the chamber for analysis on 1, 7, 15, 30, 45 and $60 \mathrm{~d}$. The first analysis included enumeration of starter and nonstarter organisms. $1 \mathrm{~d}$ sample was prepared immediately after cheese production. Appropriate dilutions were made for each strain into petriplates and pour plated with tempered $\left(45^{\circ} \mathrm{C}\right)$ BactoR M17 agar or Rogosa agar [8]for starters and nonstarters, respectively. Anaerobic status was evaluated by an anaerobic indicator strip in the chamber.

\subsection{Determination of WSN}

Total nitrogen (TN), expressed as crude protein on dry weight basis, was determined by using the Kjeldahl procedure [9].We measured the level of WSN using Kjeldahl method. The filtrate expressed as a percentage of total nitrogen in cheese was analyzed by the macro-bloc digestion method.

\subsection{Sensory analysis}

Typically, the change of the texture is one of the most important quality characteristics of cheese ripening[10]. The change of hardness and elastic changes were determined as indicators in this test. The sensory evaluation was carried out by 50 trained panelists; each one assessed the cheeses separately taking into account the following features: flavor and appearance. The scales for flavor and consistency were: 1 , bad; 2 , sufficient; 3 , good; 4 , very good and for firmness was: 1 , soft; 2 , normal; 3 , firm/hard. The averages data with standard deviations were determined and expressed as \pm means.

\section{Results and Discussion}

\subsection{Composition of cheese}

As shown in table 1, the content of components in the test meet the standard Cheddar cheese ( the Cheddar cheese ripened contain less than $39 \%$ water, $32 \%$ fat, $25 \%$ protein, salt $1.4 \%$ to $1.8 \%$ ). This indicated that no significant differences were found between the control slurries and those which were added the isolated Lactobacillus plantarum during ripening.

Table 1 The $\mathrm{pH}$ and composition of Cheddar cheeses

\begin{tabular}{ccccc}
\hline cheese & protein $\%$ & fat $\%$ & salt $\%$ & moisture\% \\
\hline test & $24.3 \pm 0.04$ & $32.5 \pm 0.2$ & $1.78 \pm 0.04$ & $38.4 \pm 0.08$ \\
control 1 & $23.3 \pm 0.05$ & $31.9 \pm 0.09$ & $1.64 \pm 0.05$ & $3.27 \pm 0.03$ \\
control & $23.8 \pm 0.08$ & $32.3 \pm 0.08$ & $1.63 \pm 0.03$ & $5.15 \pm 0.06$ \\
\hline
\end{tabular}

\subsection{Cheese microbiological characteristics}

The mean populations of Lactobacillus plantarum on cheese ripening 1,7,15,30,45,60 $\mathrm{d}$ are shown in Fig.1. The initial counts of nonstarter were approximately $2.9 \times 103 \mathrm{cfu} / \mathrm{g}$. After two months of maturity, the concentration of Lactobacillus reached to $2.1 \times 107 \mathrm{cfu} / \mathrm{g}$. With slow-growing the 
concentration of the Lactobacillus was $3.8 \times 103 \mathrm{cfu} / \mathrm{g}$ on $30 \mathrm{~d}$, indicating that the populations of nonstarter in control group of cheese which was pasteurized and without adding Lactobacillus was significantly lower than that in the test group, and even before $30 \mathrm{~d}$.
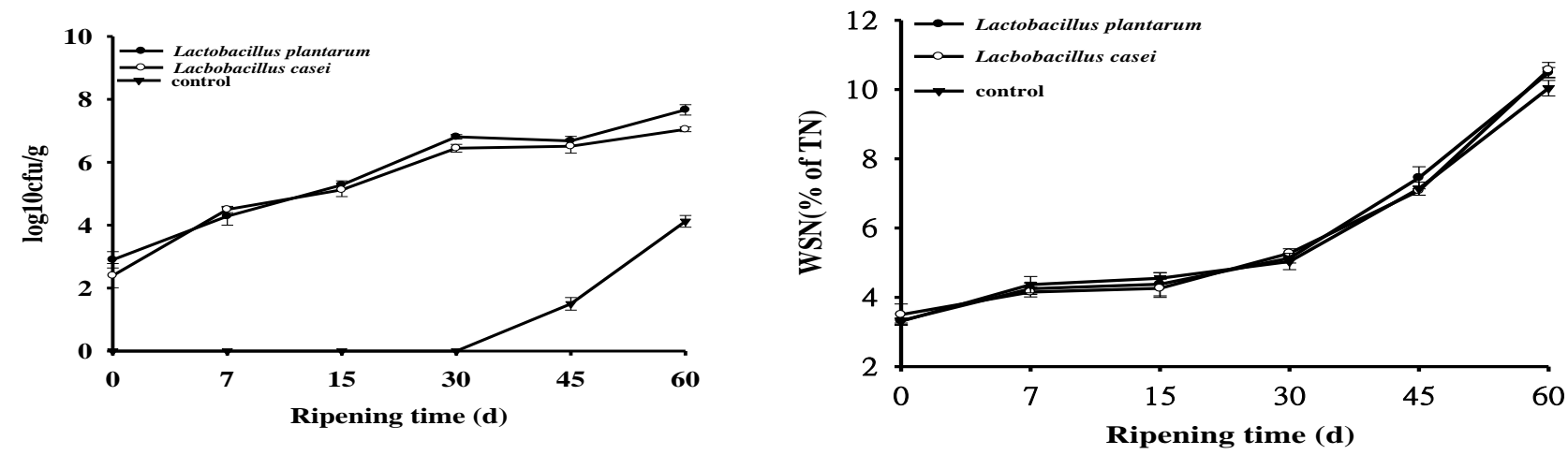

Fig. 1 The change of non-starter counts during ripening Fig. 2 WSN of cheese ripened for 0 to $60 \mathrm{~d}$

\subsection{Nitrogen fractions}

In the present study, the concentration of WSN increased significantly in both control and test cheese during maturation (Fig. 2). However, no significant differences were observed between the levels of control and test cheese $(\mathrm{P}>0.05)$. We found at all ripening times the nonstarters added did not show effect on the primary proteolysis. A similar result was also reported by Michaelidou et al. in slurries ripened[11].

\subsection{Sensory analysis}

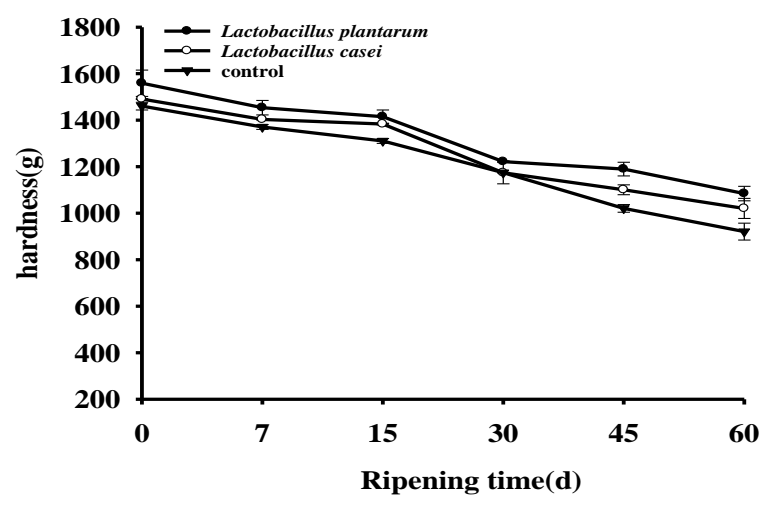

Fig. 3 TPA hardness of Cheddar cheese during ripening

It is shown in Fig. 3 that the overall trends in first and then the hardness decreased in the two test groups' cheese during maturation. The organization of state and flavor evaluation of the test group is slightly better than that of the control group because the strain Lactobacillus plantarum added accelerated the hydrolysis of the cheese protein to promote the formation of cheese flavor.

\section{Summary}

In conclusion, the nonstarter Lactobacillus plantarum influenced proteolysis. Hence, the highest level of secondary proteolysis indices made in the current study showed that cheese maturation was accelerated by the addition of the strain Lactobacillus plantarum. Furthermore the strain Lactobacillus plantarum improved cheese sensory and texture and promoted the formation of cheese flavor cream.

\section{Acknowledgements}

This work was supported by the open project of Grain \& Corn Engineering Technology Research Center, China State Administration of Grain; Heilongjiang Province Postdoctoral Science Foundation; 
Foundation for Excellent Academic Leaders of Harbin (2013RFXYJ049 and 2016RAXYJ085); College project of Heilongiiang Academy of Agricultural Sciences(2017BZ14); Postdoctoral international academic exchange program.

\section{References}

[1]. J.Darukaradhya, M.Phillips, \& K.Kailasapathy, Selective enumeration of $<\mathrm{i}>$ Lactobacillus acidophilus $</ \mathrm{i}\rangle,\langle\mathrm{i}>$ Bifidobacterium $</ \mathrm{i}>$ spp., starter lactic acid bacteria and non-starter lactic acid bacteria from Cheddar cheese. International Dairy Journal, 16(5), 439-445(2006).

[2]. L.Settanni, \& G.Moschetti, Non-starter lactic acid bacteria used to improve cheese quality and provide health benefits. Food Microbiol, 27(6), 691-697 (2010).

[3]. M. M. Milesi, G. Vinderola, N.Sabbag, C. A.Meinardi, \& E.Hynes, Influence on cheese proteolysis and sensory characteristics of non-starter lactobacilli strains with probiotic potential. Food Research International, 42(8), 1186-1196(2009).

[4]. M.Fenelon, \& T. Guinee, The effect of milk fat on Cheddar cheese yield and its prediction, using modifications of the Van Slyke cheese yield formula. Journal of Dairy Science, 82(11), 2287-2299(1999).

[5]. M.Johnson, C.Chen, \& J.Jaeggi, Effect of rennet coagulation time on composition, yield, and quality of reduced-fat Cheddar cheese. Journal of Dairy Science, 84(5), 1027-1033(2001).

[6]. S.Menéndez, R.Godínez, J.Centeno, \& J.Rodríguez-Otero, Microbiological, chemical and biochemical characteristics of 'Tetilla'raw cows-milk cheese. Food Microbiol, 18(2), 151-158(2001).

[7]. P. Fox, Proteolysis during cheese manufacture and ripening. Journal of Dairy Science, 72(6), 1379-1400(1989).

[8]. B.E.Terzaghi, \& W.Sandine, Improved medium for lactic streptococci and their bacteriophages. Applied microbiology, 29(6), 807-813(1975).

[9]. U. Bütikofer, M.Rüegg, \& Y.Ardö, Determination of nitrogen fractions in cheese: Evaluation of a collaborative study. LWT-Food Science and Technology, 26(3), 271-275(1993).

[10]. A.Pollard, F.Sherkat, M.Seuret, \& A.Halmos, Textural changes of natural Cheddar cheese during the maturation process. Journal of Food Science, 68(6), 2011-2016(2003).

[11]. A.Michaelidou, M.Katsiari, E.Kondyli, L.Voutsinas, \& E.Alichanidis, Effect of a commercial adjunct culture on proteolysis in low-fat Feta-type cheese. International Dairy Journal, 13(2), 179-189(2003). 